\title{
Evidence-based education for the future in the European Society for Sports traumatology, Knee surgery and Arthroscopy (ESSKA)
}

\author{
Martin Lind ${ }^{1}(1) \cdot$ Romain Seil $^{2,3} \cdot$ David Dejour $^{4} \cdot$ Roland Becker $^{5} \cdot$ Jacques Menetrey $^{6,7} \cdot$ Michael Ross $^{8}$
}

Received: 19 August 2020 / Accepted: 21 August 2020 / Published online: 1 September 2020

(c) European Society of Sports Traumatology, Knee Surgery, Arthroscopy (ESSKA) 2020

The profession of orthopedic surgery is constantly evolving. Fast surgical and technological progress, new forms of communication and social media, commercial pressures, deep changes in society and patient expectations, gender and generational changes among surgeons, and the shifting economic landscapes of European healthcare environments are major cornerstones of this process. The level of surgical specialization and standardization of orthopedic procedures has increased, while postgraduate and continuing professional education and training remain highly diverse. The principles of surgical education and training are anchored in the nineteenth century [8]. They are complex and, in addition to physicians' fundamental qualities like the theoretical understanding of their specialty and empathy towards patients, surgeons need to acquire advanced motor skills which need to be learned in safe and secure environments

Martin Lind

martinlind@dadlnet.dk

1 Department of Orthopedics, Aarhus University Hospital, Palle Juul Jensens Boulevard 99, 8200 Aarhus N, Denmark

2 Department of Orthopaedic Surgery, Centre Hospitalier de Luxembourg-Clinique d'Eich, 8, Rue d Eich, 1460 Luxembourg, Luxembourg

3 Luxembourg Institute of Health, 8, Rue d Eich, 1460 Luxembourg, Luxembourg

4 Lyon-Ortho-Clinic, Clinique de la Sauvegarde, Bat B 29 Avenue des Sources, 69009 Lyon, France

5 Department of Orthopedics and Traumatology, Centre of Joint Replacement, Hospital Brandenburg, Medical School "Theodor Fontane", Hochstrasse 2, 14770 Brandenburg/Havel, Germany

6 Centre de Médecine du Sport et de l'Exercice, Swiss Olympic Medical Center, Hirslanden Clinique La Colline, Av. de la Roseraie 76B, 1206 Geneva, Switzerland

7 Division of Orthopaedic Surgery, University Hospital of Geneva, Geneva, Switzerland

8 NHS Fife, Hayfield House, Hayfield Road, Kirkcaldy KY2 5AH, UK
$[3,4]$. Despite having significantly improved over the last 15 years, education and training in the fields of interest of ESSKA (the European Society for Sports Traumatology, Knee Surgery and Arthroscopy) still lack harmonization [5]. When the ESSKA leadership analyzed the development of the field over the last 15 years and the changing needs of their members, it appeared that postgraduate and subsequent super-specialized education and training were insufficiently structured and standardized across Europe, and it, therefore, seemed urgent to develop new and well-defined educational pathways for these [8]. Therefore, ESSKA now has developed a core curriculum which may help to harmonize specialty and postgraduate training of orthopedic surgeons [2,7].

A core curriculum represents a shared understanding of what individuals working in discrete specialist areas need to be able to do and is a living document which can be updated over time as circumstances and technologies change. It enables teachers to communicate with trainees about what to learn, to tailor their teaching appropriately, and to develop fair and reliable assessments. It helps trainees reflect on their progress and experience in different areas, identify what they need to practice and study, and actively seek out opportunities and resources to address gaps in their learning. A core curriculum also provides clinical experts, leaders, and academics with a common language to discuss their clinical and educational practice, share expertise and resources between specialties and countries, and collaborate and undertake relevant research. An evidence-based core curriculum also inherently promotes best practice based on research and a broad base of expert opinion, and thus helps to address issues of clinical governance, regional variation, cost-effectiveness, and patient safety. Clinicians are not limited to learning only the contents of a core curriculum, either during their training or specialist practice, and will inevitably develop other competencies arising from their own individual experience, preferences and the needs of the healthcare system, and context in which they work. There 
also remains an ongoing need for the scholarly exploration of alternative, new, and experimental approaches to clinical practice-continually seeking to improve practice and the care of individual patients. A core curriculum provides a common frame of reference and 'gold standards' against which such developments can be related and, if the evidence is favorable, these might be incorporated into future iterations of the curriculum.

To develop a core curriculum that scientifically could support the educational activities of ESSKA, several important decisions were taken. The curriculum would be defined in terms of clinical competencies, to optimally guide clinicians to pursue education that would lead to them being able to safely undertake defined procedures and thus improve patient care. The curriculum would cover all of ESSKA's specialist areas of Knee, Shoulder, Foot/Ankle, Hip, Elbow/ Forearm, and Sports/Exercise. The definition of core competencies would be based on a dual strategy of seeking the highest possible expertise within each specialist area as well as the opinions of the entire ESSKA membership. To fulfill these priorities, expert groups from each specialist area representing leaders and other experts developed a draft list of 285 core competencies that was subsequently rated and evaluated by the ESSKA membership, resulting in refinement of the curriculum.

National authorities are responsible for education and training of doctors. However, the duration, format, and content of specialty training and continuing professional development in Orthopedics and Traumatology, for example, vary remarkably between European countries. Quality standards are not clearly defined in detail at the European level, but specialists are free to move and practice Medicine throughout the European Community. The harmonization of training between the different countries of Europe is supported by international societies and organizations. ESSKA provides an ideal platform for communication and discussion about training and educational programs for specializing in Orthopedics and Sports Medicine, and has done so for many years. EFORT already defined the main topics for postgraduate Orthopedics and Traumatology across Europe on a general basis. The Fellowship examination of the European Board of Orthopaedics and Traumatology (EBOT) was established in 2001. Every trainee or Orthopedics Surgeon throughout Europe can take the exam, which is now well recognized.

Continued education in medicine is very important. The Union Européenne des Médecins Spésialistes (UEMS) was founded in 1958 to represent the interest of specialist doctors on an international level, and in 2000, the European Accreditation Council for Continuing Medical Education (EACCME) was established. National and international congresses and courses and other educational activities are certified by them, and the credits are recognized by many countries throughout Europe. ESSKA is not only well known due to the biannual meeting but also due to all the different activities in providing education to the Orthopedic and sports Medicine community. ESSKA organizes many courses and fellowships every year teaching the most recent surgical techniques and providing the latest knowledge in Orthopedics and Sports Medicine. A core curriculum developed by ESSKA will help to structure courses better and to harmonize the content of these courses with those offered by other organizations, to develop teaching centers, and to help teachers deliver relevant and structured education.

The Committees and Sections of ESSKA were founded many years ago to develop a network of highly specialized Orthopedics Surgeons throughout Europe and other parts of the world, in recognition that sharing knowledge and experience in Orthopedics and Sports Medicine improves patient care and evidence-based practice. An ongoing critical review and revision of clinical practice is also very important because of the discrepancy which can sometimes arise between existing practice and advancing scientific knowledge. Consensus statements help to solve these gaps, as shown recently with the European Meniscus Consensus and Allograft Initiative projects [1, 6, 9]. Clinical and basic science is published in both KSSTA and JEO, the official journals of ESSKA. Congresses, course, and fellowship programs and the journals are the most important and independent pillars of the scientific and educational efforts of ESSKA.

The ESSKA core curriculum is a fantastic tool to guide clinicians, the ESSKA leadership, and other educational providers to pursue and provide training that will lead to the most relevant clinical competencies in these key musculoskeletal areas. Within ESSKA, the ESSKA-Academy educational platform will now be organized around the core curriculum to offer a direct entry to educational material that support the all relevant competency development. The growth of a young surgeon relies on the mentorship of the elders [3]. This is the core of our profession which enables an intelligent mix between scientific knowledge, practical skills, and role modeling. The core curriculum provides a frame for post-specialist education, and the courses, meetings, and scientific events are the pictures which we will put inside.

ESSKA provides all these educational activities without commercial bias. Future ESSKA "All About" courses will be organized to fulfill the most important competencies as described in the core curriculum. Also, ESSKA will aim to develop and increase course capacity to give ESSKA members all the most important clinical competencies through our educational portfolio.

Finally, the core curriculum and its body of knowledge serve as the basis of a well-structured ESSKA education program. It will not prevent ESSKA from continuing to deliver the most recent surgical techniques, updating scientific 
knowledge and practical analysis, with, for instance, consensus statements, which have proven to be so valuable to our members in their daily practice.

\section{References}

1. Beaufils P, Becker R, Kopf S, Englund M, Verdonk R, Ollivier $M$ et al (2017) Surgical management of degenerative meniscus lesions: the 2016 ESSKA meniscus consensus. Joints 5:59-69

2. de Girolamo L, Dejour D, Lind M, Karlsson J, Seil R (2020) Surgical competence, research and evidence-based medicine (EBM) in orthopaedic surgery: what the ESSKA is doing to bring it all together. Knee Surg Sports Traumatol Arthrosc 28:335-338

3. Dejour DH (2018) The role of a scientific society in the training and development of an orthopaedic surgeon. Knee Surg Sports Traumatol Arthrosc 26:3197-3198

4. Espregueira-Mendes J, Karahan M (2014) Orthopaedic sports surgery: art or science? Knee Surg Sports Traumatol Arthrosc 22:959-960

5. Georgoulis A, Randelli P (2011) Education in arthroscopy, sports medicine and knee surgery. Knee Surg Sports Traumatol Arthrosc 19:1231-1232
6. Kopf S, Beaufils P, Hirschmann MT, Rotigliano N, Ollivier M, Pereira $\mathrm{H}$ et al (2020) Management of traumatic meniscus tears: the 2019 ESSKA meniscus consensus. Knee Surg Sports Traumatol Arthrosc 28:1177-1194

7. Lind M, Seil R, Dejour D, Becker R, Menetrey J, Ross M (2020) Creation of a specialist core curriculum for the European Society for Sports traumatology, Knee surgery and Arthroscopy (ESSKA). Knee Surg Sports Traumatol Arthrosc. https://doi.org/10.1007/ s00167-020-06210-2

8. Seil R (2019) Why ESSKA? On what it takes for orthopaedic surgeons and their scientific societies to adapt to societal changes in 2018. Knee Surg Sports Traumatol Arthrosc 27:665-672

9. Spalding T, Verdonk P, de Girolamo L, Seil R, Dejour D (2019) Allografts in joint reconstruction: ESSKA making a difference. Knee Surg Sports Traumatol Arthrosc 27:1701-1703

Publisher's Note Springer Nature remains neutral with regard to jurisdictional claims in published maps and institutional affiliations. 